\title{
Magnitude of visceral leishmaniasis and poor treatment outcome among HIV patients: meta- analysis and systematic review
}

This article was published in the following Dove Press journal:

HIVIAIDS - Research and Palliative Care

23 March 2016

Number of times this article has been viewed

\author{
Mekuriaw Alemayehu' \\ Mamo Wubshet' \\ Nebiyu Mesfin² \\ 'Environmental and Occupational \\ Health and Safety Department, \\ Institute of Public Health, ${ }^{2}$ Internal \\ Medicine Department, School of \\ Medicine, College of Medicine and \\ Health Sciences, University of Gondar, \\ Gondar, Ethiopia
}

Correspondence: Mekuriaw Alemayehu Institute of Public Health, College of Medicine and Health Sciences, University of Gondar, PO Box 196, Gondar, Ethiopia Tel +25 I 9 205। 0050

Email mekuriawbetty@gmail.com
Background: Visceral leishmaniasis (VL) coinfection with HIV/AIDS most often results in unfavorable responses to treatment, frequent relapses, and premature deaths. Scarce data are available, regarding the magnitude and poor treatment outcomes of VL-HIV coinfection.

Objective: The main objective of this systematic review was to describe the pooled prevalence of VL and poor treatment outcome among HIV patients.

Review methods: Electronic databases mainly PubMed were searched. Databases, such as Google and Google scholar, were searched for gray literature. Articles were selected based on their inclusion criterion, whether they included HIV-positive individuals with VL diagnosis. STATA 11 software was used to conduct a meta-analysis of pooled prevalence of VL-HIV coinfection.

Results: Fifteen of the 150 articles fulfilled the inclusion criteria. A majority of the study participants were males between 25 years and 41 years of age. The pooled prevalence of VL-HIV coinfection is $5.2 \%$ with $95 \%$ confidence interval of (2.45-10.99). Two studies demonstrated the impact of antiretroviral treatment on reduction in relapse rate compared with patients who did not start antiretroviral treatment. One study showed that the higher the baseline CD4+ cell count $(>100$ cells $/ \mathrm{mL}$ ) the lower the relapse rate. Former VL episodes were identified as risk factors for relapse in two articles. In one of the articles, an earlier bout of VL remains significant in the model adjusted to other variables.

Conclusion: The pooled prevalence of VL in HIV-infected patients is low and an earlier bout of VL and CD4+ count $<100$ cells/mL at the time of primary VL diagnosis are factors that predict poor treatment outcome.

Keywords: visceral leishmaniasis, HIV coinfection, magnitude

\section{Introduction}

Visceral leishmaniasis (VL also called "kala-azar") is a protozoan disease caused by the leishmania species complex. An estimated 500,000 new cases of kala-azar occur annually. ${ }^{1}$ HIV infection can lead to reactivation of leishmania infection or to symptomatic kala-azar at initial infection; in Europe, the risk of developing VL is 100-1,000 times greater for HIV-positive individuals when compared with HIVnegative individuals. ${ }^{2,3}$ The HIV/AIDS pandemic has modified the natural history of leishmaniasis. ${ }^{4}$ Kala-azar increases HIV replication and disease progression, mainly by chronic immune stimulation. ${ }^{5}$ Both diseases exert a synergistic detrimental effect on the cellular immune response because they target similar immune cells. ${ }^{6}$

The prevalence of patients with concordant HIV infection and VL in Europe has fallen sharply since 1996, when antiretroviral treatment (ART) became standard. In India and particularly in Africa, VL-HIV coinfection is emerging. The AIDS pandemic has expanded 
to rural areas where VL is endemic, with cases of HIV-VL coinfection reported in 35 countries. ${ }^{7,8} \mathrm{VL}$ is generally considered as an opportunistic infection in patients coinfected with HIV and often presents with atypical clinical features. ${ }^{9}$ VL-HIV coinfected patients are at a greater risk of relapse and death. Moreover, VL adversely affects the response to ART., ${ }^{6,9}$

Recent changes in epidemiological trends of HIV and leishmania infections possibly lead to a greater degree of overlap and a greater risk of coinfection, and they justify increased alertness. VL coinfection with HIV/AIDS most often results in unfavorable responses to treatment, frequent relapses, and premature deaths. Scarce data are available, regarding the magnitude and poor treatment outcomes of VL-HIV coinfection. This article is a systematic review of studies describing the magnitude and factors for poor treatment outcome of VL-HIV coinfected patients.

\section{Methods}

First DARE database (http://www.library.UCSF.edu) was explored in an attempt to confirm whether systematic review or meta-analysis exists and for availability of ongoing projects related to the topic. The titles of all appropriate abstracts and titles collected from electronic and hand searches were entered into the Endnote version 7.0 software (Thomson Reuters, NY, USA).

This systematic review included all papers that were published up till August 1, 2015. To ensure scientific rigor, the Preferred Reporting of Systematic Reviews and MetaAnalysis (PRISMA) guidelines ${ }^{10}$ were used for systematic data synthesis. Main sources for the review were electronic bibliographic databases, especially MEDLINE. Databases, such as Google and Google scholar, were searched, especially for gray literature. The search terms used as keywords and/ or MeSH terms are mentioned in Figure 1.

\section{Eligibility criteria}

Each study was assessed as to whether it met the eligibility criteria as stated in Table 1.
There were no restrictions on date of publication, use of secondary prophylaxis, or duration of follow-up in the study but there was restriction on publication language. The chosen studies were read in full to confirm eligibility. Data were extracted directly from the full-length article to structured tables containing all of the necessarily variables and outcomes' of interest. The following information was extracted: country and period of enrollment, sample size, objective of the study, method, VL diagnosis method, study participants, and main findings.

\section{Results}

The selection process is illustrated in Figure 2. Among 150 studies, 125 were excluded because they did not meet the inclusion criteria following reading titles and/or abstracts. Ten more articles were excluded after reading the entire article: three were review ${ }^{11-13}$ and seven ${ }^{14-20}$ did not evaluate the magnitude of VL-HIV coinfection. Thus, 15 studies fulfilled the stated inclusion criteria and constituted the basis of this investigation.

\section{Studies and patients}

Table S1 summarizes the characteristics of the 1,781 coinfected patients encompassed by the 15 included studies. The year of articles publication ranged from 1998 to 2015. Seven of the articles used retrospective study design, four others prospective, two were cross-sectional, one was institution based case series, and one both retrospective and prospective. Six studies were reported in Ethiopia, three in Brazil, three in India, and three in Spain. All 15 articles had an enrollment period exclusively after 1989, when highly active antiretroviral therapy (HAART) became available. Eleven studies stated the proportions of patients receiving HAART involving two nucleoside reverse transcriptase inhibiters and one or two protease inhibiters, or nonnucleoside reverse transcriptase inhibiters at VL diagnosis, or at relapse, or both.

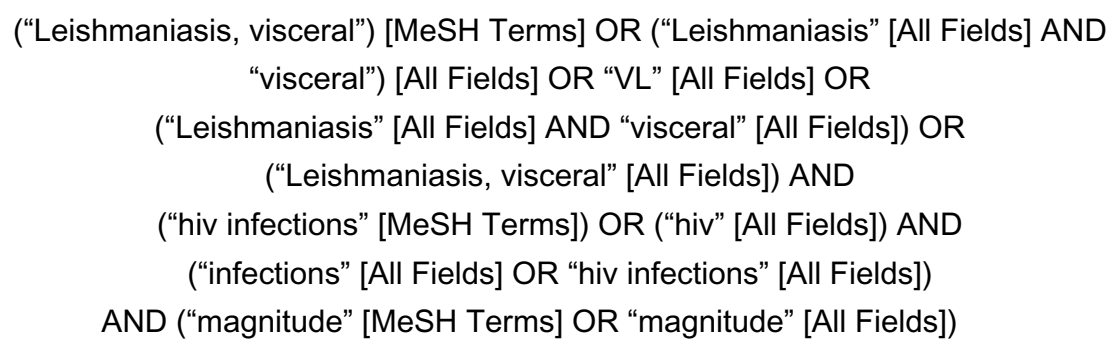


Table I Inclusion and exclusion criteria of articles reviewed

\begin{tabular}{ll}
\hline Inclusion criteria & Exclusion criteria \\
\hline $\begin{array}{l}\text { Presented in an original } \\
\text { article }\end{array}$ & Articles dealing with less than ten cases \\
$\begin{array}{l}\text { Articles that examined } \\
\text { VL diagnosis among HIV- }\end{array}$ & $\begin{array}{l}\text { Articles dealing with mixed population } \\
\text { of HIV-infected and uninfected subjects } \\
\text { unless separated results for HIV } \\
\text { infected individuals }\end{array}$ \\
& $\begin{array}{l}\text { patients were identified } \\
\text { Non English literature }\end{array}$ \\
\hline
\end{tabular}

Notes: aliterature written other than in English language was not included in this study.

Abbreviation: VL, visceral leishmaniasis.

Large proportions of the patients in these studies (74.7\%) were male and most were young adults: the median or mean ages reported varied from 25 years to 41 years. In eight of the studies complete CD4+ lymphocyte of the patients were reported during diagnosis of VL-HIV coinfection. The median or mean CD4+ lymphocyte count in these studies ranged from 33 cells $/ \mu \mathrm{L}$ to 172 cells $/ \mu \mathrm{L} .{ }^{21-28}$

In most of the articles, the diagnosis of VL was made on clinical presentation (World Health Organization case definition was used as a starting point: fever for $>2$ weeks excluding malaria, in combination with splenomegaly and/or wasting ${ }^{29}$ ) confirmed by either 1) positive serology test if the patient has no VL history or 2) demonstration of parasite from spleen or lymph node aspiration. In one study, ${ }^{30}$ the VL diagnosis was done only by using rK39 kit (indirect immunofluorescence or rK-39 dipsticks) serologic test. Four studies ${ }^{21,22,31,32}$ also included patients diagnosed by only searching for leishmania amastigotes in bone marrow/lymph node aspirates. In one study, ${ }^{33}$ the VL among the HIV-infected individuals was diagnosed by ELISA, and the result was confirmed by either indirect immunofluorescence or Western blot analysis.

The drug used in the treatment of VL is reported for $59.7 \%$ of the treated patients. Of this total, $45 \%$ of cases (464 patients) were treated with liposomal amphotricine B (AmBisome, Gilead Sciences Ltd., Paris, France) drug, $34.5 \%$ with sodium stibogluconate (356 patients), and 9.9\% (102 patients) received a combination of AmBisome divided into six equal dose infusions given on alternate days, concurrently with 14 days of oral miltefosine. In one study, ${ }^{34}$ pentavalent antimonials (sodium stibogluconate or meglumine antimoniate) was used as first-line antileishmanial treatment and liposomal amphotericin B (AmBisome) from Gilead Sciences Ltd., Paris, France was used as second-line treatment in patients not tolerating antimonials and in critically ill patients. A minority of patients $(0.19 \%)$ received pentamidine, and two patients $(0.19 \%)$ were also treated by using amphotericin B lipid complex. ${ }^{21}$

Eight of the 15 studies evaluated the dose of the treatment along with the treatment outcome. One study ${ }^{23}$ clearly showed the limited effectiveness of high-dose AmBisome (ranged from $25 \mathrm{mg} / \mathrm{kg}$ to $40.5 \mathrm{mg} / \mathrm{kg}$, median of $30 \mathrm{mg} / \mathrm{kg}$ ).

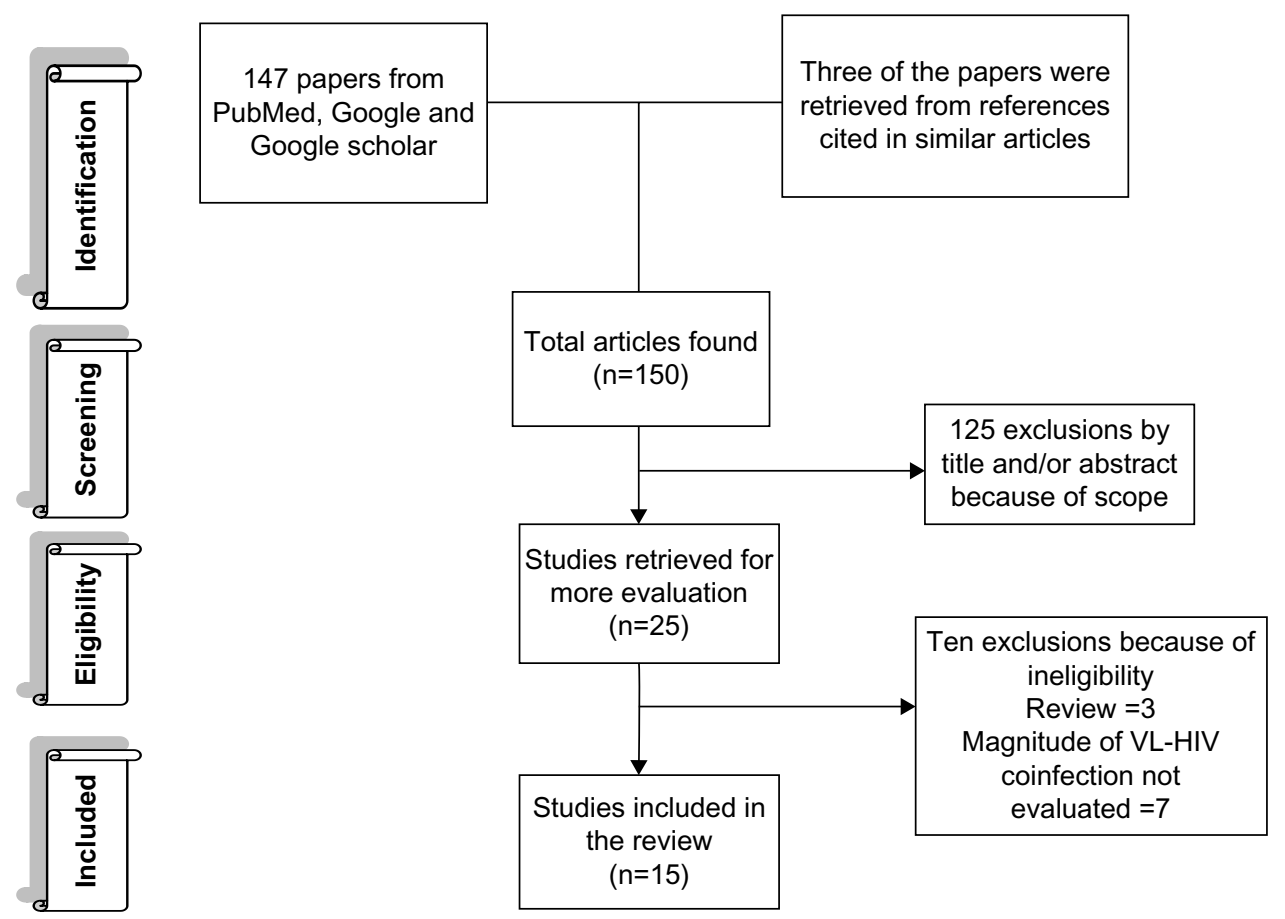

Figure 2 Study selection process. 
Five of the earlier studies also showed that a total dose of $20 \mathrm{mg} / \mathrm{kg}$ or $25 \mathrm{mg} / \mathrm{kg}$ AmBisome was not fully effective to cure VL in VL-HIV coinfected patients. In one study, ${ }^{25}$ VL patients coinfected with HIV were treated as inpatients using a combination of $30 \mathrm{mg} / \mathrm{kg}$ body weight AmBisome divided into six equal dose infusions given on alternate days, concurrently with 14 days of oral miltefosine. The dose of miltefosine was calculated according to the patient's weight ( $\geq 25 \mathrm{~kg}, 50 \mathrm{mg}$ twice daily; weight $12 \mathrm{~kg}$ to $<25 \mathrm{~kg}, 50 \mathrm{mg}$ once daily). Completion of the treatment was associated with a significant decrease in the size of spleen and liver at the time of discharge from the hospital.

A test of cure at the end of the treatment was carried out in four of 15 studies. In one study, ${ }^{24}$ test of cure was not routinely performed due to the risks associated with splenic puncture, instead "initial cure" was considered following World Health Organization $^{35}$ descriptions of treatment response (when the patients showed clinical improvement, cessation of fever, reduction in spleen size, and return of appetite at the time of discharge).

Three studies ${ }^{24-26}$ that evaluated VL treatment in HIV coinfected patients and one study ${ }^{31}$ that evaluated the clinical presentation of VL-HIV coinfected patients included only VL-HIV coinfected patients during their study. Therefore, we excluded these papers from meta-analysis of pooled prevalence of VL-HIV coinfection. A meta-analysis of results from eleven studies evaluating the magnitude of VL-HIV coinfection is shown in Figure 3. This analysis could consistently demonstrate the prevalence of VL-HIV coinfection. The pooled estimate of the prevalence from eleven studies is $5.2 \%$ with confidence interval of $(2.45 \%-10.99 \%)$. We used funnel plots to visually assess the possibility of publication bias in our meta-analysis. The result of our analysis was a symmetric funnel plot, and this indicates that there is a possible absence of publication bias.

Relapse of VL was reported in eight of the 15 studies. Three studies explored the impact of ART on relapse of VL. ${ }^{21,24,27}$ Two studies demonstrated a reduction in relapse rate compared with patients who did not undergo ART. Only one ${ }^{21}$ of these studies demonstrated the reduction in symptomatic VL relapse in patients with secondary chemoprophylaxis after the beginning of HAART. Similarly, one ${ }^{24}$ study that followed patients on ART at VL diagnosis reported a decreased risk of mortality.

CD4+ lymphocyte count at VL diagnosis and followup has been studied in relation to risk of relapse. Four articles $^{21,24,27,36}$ compared CD4+ lymphocyte cell counts at VL diagnosis between relapsing and nonrelapsing patients as a dichotomous variable. Only one ${ }^{27}$ of these studies showed significant difference between these two groups. It was noted that the arms with higher CD4+ count $(>100$ cells $/ \mathrm{mL})$ had lower relapse rate. In the same study, VL relapses were sometimes seen, despite high CD4+ cell counts - in $28 \%$ of first relapses during follow-up, the preceding CD4+ cell count was $>200$ cells $/ \mathrm{mL}$, and in $10 \%$ of first relapses, it was $>350$ cells $/ \mathrm{mL}$.

Other variables explored in relation to relapse are shown in Table S2. Factors, such as age, various clinical findings, specific antileishmaniasis treatment given, time from VL diagnosis to the introduction of ART, and ART compliance, were not substantially different between relapsing and nonrelapsing patients. Concordant tuberculosis ${ }^{27}$ infection was examined in multivariate analysis, and it became an independent predictor for the occurrence of VL relapse. Former VL bouts were identified as risk factors for relapse in two articles, in one of the articles, former VL bouts remain significant in multivariate analysis.

\section{Statistical analysis}

The statistical quality and the presentation of methods and results in many studies were poor. In five studies, the Kaplan-Meier method was used in univariant survival analysis to analyze the cumulative incidence of outcomes (primary VL, relapse VL, and mortality). Two prospective and three retrospective cohort studies used Cox regression for multivariate analysis of independent risk factors. Eight studies used multivariate logistic regression analysis to identify independent predictors. Twelve of the abovementioned studies did not conduct collinearity assessment (ie, a high degree of correlation between two predictive values) or developed a risk score for primary or relapse of VL based on their multivariable result. In one study, ${ }^{24}$ collinearity was evaluated by calculating the variance inflation factors. In addition, 12 of the abovementioned studies did not report a goodness-of-fit test of their models during multivariate analysis. In one study, ${ }^{28}$ the Hosmer-Lemeshow goodness-of-fit test was used to evaluate the model fitness during the multivariate analysis. Other studies analyzed their findings by using descriptive statistics.

\section{Discussion}

This study is a meta-analysis and systematic review of the magnitude and poor treatment outcome of VL among HIVinfected patients. Our main conclusion is that the magnitude of VL in HIV-infected patients is low (5.2\%). We also found 


\begin{tabular}{|c|c|c|c|c|}
\hline \multicolumn{5}{|l|}{ Study } \\
\hline \multicolumn{4}{|l|}{ ter Horse et $a^{27}$} & \\
\hline \multicolumn{5}{|l|}{ Ritmeijer et al ${ }^{23}$} \\
\hline \multicolumn{5}{|l|}{ Hurissa et $\mathrm{al}^{34}$} \\
\hline \multicolumn{5}{|l|}{ Mira et $\mathrm{al}^{21}$} \\
\hline \multicolumn{5}{|l|}{ de La Rosa et al ${ }^{32}$} \\
\hline \multicolumn{5}{|l|}{ Pineda et $\mathrm{al}^{22}$} \\
\hline \multicolumn{5}{|l|}{ Yimer et $\mathrm{al}^{30}$} \\
\hline \multicolumn{5}{|l|}{ Lyons et al ${ }^{41}$} \\
\hline \multicolumn{5}{|l|}{ Cota et $\mathrm{al}^{28}$} \\
\hline \multicolumn{5}{|l|}{ Albuquerque et $\mathrm{al}^{33}$} \\
\hline \multicolumn{5}{|l|}{ Mengistu and Ayele ${ }^{36}$} \\
\hline \multicolumn{5}{|l|}{ Overall $\left(I^{2}=22.3 \%, P=0.231\right)$} \\
\hline & & & 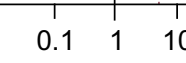 & \\
\hline Study & ES & \multicolumn{2}{|c|}{ [95\% confidence interval] } & $\%$ weight \\
\hline ter Horse et $\mathrm{al}^{27}$ & 31.022 & 3.975 & 242.120 & 10.53 \\
\hline Ritmeijer et $\mathrm{al}^{23}$ & 67.474 & 0.304 & $1.5 e+04$ & 1.86 \\
\hline Hurissa et al ${ }^{34}$ & 38.174 & 0.083 & $1.8 e+04$ & 1.46 \\
\hline Mira et $\mathrm{al}^{21}$ & 5.073 & 1.796 & 14.332 & 25.47 \\
\hline de La Rosa et $a^{32}$ & 4.384 & 0.701 & 27.427 & 12.55 \\
\hline Pineda et $\mathrm{al}^{22}$ & 10.997 & 0.302 & 400.231 & 4.02 \\
\hline Yimer et $\mathrm{al}^{30}$ & 18.093 & 0.434 & 754.696 & 3.75 \\
\hline Lyons et al ${ }^{41}$ & 23.005 & 0.081 & $6,552.833$ & 1.71 \\
\hline Cota et $\mathrm{al}^{28}$ & 51.111 & 0.002 & $1.6 e+06$ & 0.52 \\
\hline Albuquerque et $\mathrm{al}^{33}$ & 1.855 & 0.991 & 3.472 & 36.87 \\
\hline Mengistu and Ayele ${ }^{36}$ & 41.038 & 0.055 & $3.1 e+04$ & 1.26 \\
\hline Pooled ES & 5.186 & 2.446 & 10.995 & 100.00 \\
\hline $\begin{array}{l}\text { Heterogeneity } \chi^{2}=12.88 \\
R^{2} \text { (variation in ES attrib } \\
\text { Estimate of between-stu }\end{array}$ & $\begin{array}{l}P=0.23 \\
\text { to hetero } \\
\text { riance } \tau^{2}=\end{array}$ & $\begin{array}{l}\text { geneity) }=2 \\
=0.2963\end{array}$ & $3 \%$ & \\
\hline Test of $E S=1: Z=4.29 \mathrm{~F}$ & & & & \\
\hline
\end{tabular}

Figure 3 Meta-analysis of pooled prevalence of VL-HIV coinfection.

Note: Weights are from random effects analysis.

Abbreviation: VL, visceral leishmaniasis; ES, estimate.

that patients who did not face poor treatment outcome (relapse or death) showed significantly higher CD4+ count at follow-up than patients without poor treatment outcome in the course of treatment. Unlike other opportunistic infections, there are some reports of VL relapse in patients with a CD4+ count $>200$ cells $/ \mathrm{mL}$ in Ethiopia. Based on this evidence, we can speculate that factors other than a $\mathrm{CD} 4+$ cell increase are involved in VL control.

It is well known that the arrival of HAART has modified the natural history of HIV infection and its opportunistic infections, including leishmaniasis. ${ }^{37}$ The beneficial effect of HAART has been demonstrated on other opportunistic infections, such as toxoplasmosis, cryptosporidiosis, and microsporidiosis. ${ }^{2,38}$ HAART did not produce the predicted decrease in the incidence of kala-azar relapse. Studies that were conducted in HAART and pre-HAART era showed a similar relapse rate. Only one ${ }^{21}$ study showed a decrease in the relapse rate among patients receiving HAART. None of the studies reported a statistically significant difference in VL relapse between patients who were receiving and not receiving HAART. So far, these disappointing findings are not in agreement with a statistically significant association between improvements in CD4+ at follow-up and decrease in VL relapse. This may be due to the small sample sizes of the studies performed, poor patient adherence to ART, or insufficient immune response. 
VL affects HIV-1 patients who exhibit a significant disturbance of cellular immunity; however, VL by itself may reduce CD4+ lymphocyte count. ${ }^{39}$ However, a CD4+ count $>100$ cells $/ \mathrm{mL}$ at $\mathrm{VL}$ diagnosis is a potential protective factor against relapse, although the analysis of this beneficial effect may be complicated by the immune suppression of many of the patients included in the studies.

Former bouts of VL were associated with relapse. This is also in line with the immune inflammatory theory; it was hypothesized that the enhancement of the Th-2 response following one early relapse could prevent the later control of VL. ${ }^{40}$

It is important to note that wide ranges of therapeutic drugs were utilized for the treatment of VL in the studies we have reviewed. There was significant difference in the relapse rate with regard to specific VL treatment used. These observations do not allow us to disprove the influence of treatments used on relapse outcome.

\section{Study limitations}

- Although we have made an extensive review, our analysis was limited to only articles published in English language; other studies that were published in different languages were excluded. In addition, our analysis includes articles with different definitions of cure and different lengths of follow-up.

- Cure is seldom defined parasitologically in these studies, and reinfection is not distinguished from relapse. None of the studies reviewed undertook assessment of cure after 6 months of follow-up.

- The evaluated populations were not homogeneous.

- The reviewed papers included patients with different degrees of immune suppression, different treatment, and prophylaxis regimens.

- The reviewed articles have differences in study design, the type of statistical methods, and the variables included in the analysis. These variations may have resulted in selection bias or low statistical power, thus hampering results.

- Most of the reviewed papers used monotherapy to treat VL-HIV coinfection, possibly leading to high rates of treatment failure and development of resistant parasites.

\section{Conclusion}

The result of the review suggests that the magnitude of VL among HIV-infected patients is low, and previous episodes of VL and CD4+ count $<100$ cells/mL at the time of primary
VL diagnosis are potential predictors of relapse. HAART did not produce the expected decrease in the incidence of VL relapse in the HAART era. This review may help clinicians in making decisions and may also help in designing future studies, such as, strong surveillance will certainly contribute to improved quality of data for decision makers in this complex scenario. More researches are needed, in order to better assess the evolution of VL in the HAART era. Clinical trials to compare the efficacy of different drugs and their role either in the treatment or in prophylaxis are required.

\section{Acknowledgment}

The authors thank all the colleagues for their help in finding the gray literature, especially those who are lecturers of University of Gondar.

\section{Author contributions}

All authors contributed toward data analysis, drafting and critically revising the paper and agree to be accountable for all aspects of the work.

\section{Disclosure}

The authors report no conflicts of interest in this work.

\section{References}

1. Desjeux P. The increase in risk factors for leishmaniasis worldwide. Trans R Soc Trop Med Hyg. 2001;95:239-243.

2. Kubar J, Marty P, Lelievre A, et al. Visceral leishmaniosis in HIV positive patients: primary infection, reactivation and latent infection: impact of the CD4+ T-lymphocyte counts. AIDS. 1998;12:2147-2153.

3. Paredes R, Munoz J, Diaz I, Domingo P, Gurgui M, Clotet B. Leishmaniasis in HIV infection. J Postgrad Med. 2003;49:39-49.

4. Alvar J, Canavate C, Gutierrez-Solar B, et al. Leishmania and human immunodeficiency virus coinfection: the first 10 years. Clin Microbiol Rev. 1997;10:298-319.

5. Wolday D, Akuffo H, Demissie A, Britton S. Role of Leishmania donovani and its lipophosphoglycan in CD4+ T-cell activationinduced human immunodeficiency virus replication. Infect Immun. 1999;67:5258-5264.

6. Olivier M, Badaro R, Medrano FJ, Moreno J. The pathogenesis of Leishmania/HIV co-infection: cellular and immunological mechanisms. Ann Trop Med Parasitol. 2003;97(suppl 1):79-98.

7. Cruz I, Nieto J, Moreno J, Cañavate C, Desjeux P, Alvar J. Leishmania/ HIV co-infections in the second decade. Indian J Med Res. 2006; 123:357-388.

8. Desjeux P, Alvar J. Leishmania/HIV co-infections: epidemiology in Europe. Ann Trop Med Parasitol. 2003;97(suppl 1):3-15.

9. WHO. Control of the Leishmaniases. Report of a Meeting of the WHO Expert Committee on the Control of Leishmaniasis; March 22-26, 2010; Geneva. Geneva: WHO; 2010:1-186.

10. Liberati A, Altman DG, Tetzlaff J, et al. The PRISMA statement for reporting systematic reviews and meta-analyses of studies that evaluate health care interventions: explanation and elaboration. PLoS Med. 2009;6:e1000100.

11. Diro E, Lynen L, Ritmeijer K, Boelaert M, Hailu A, van Griensven J. Visceral leishmaniasis and HIV coinfection in East Africa. PLoS Negl Trop Dis. 2014;8(6):e2869. 
12. Cota GF, de Sousa MR, Rabello A. Predictors of visceral leishmaniasis relapse in HIV infected patients: a systematic review. PLoS Negl Trop Dis. 2011;5(6):e1153.

13. Lindoso JA, Cota GF, da Cruz AM, et al. Visceral leishmaniasis and HIV coinfection in Latin America. PLoS Negl Trop Dis. 2014;8(9):e3136.

14. Cota GF, de Sousa MR, de Freitas Nogueira BM, et al. Comparison of parasitological, serological, and molecular tests for visceral leishmaniasis in HIV-infected patients: a cross-sectional delayed-type study. Am J Trop Med Hyg. 2013;89(3):570-577.

15. Abdo MG, Elamin WM, Khalil EA, Mukhtar MM. Antimony-resistant Leishmania donovani in Eastern Sudan: incidence and in vitro correlation. East Mediterr Health J. 2003;9(4):837-843.

16. Burza S, Sinha PK, Mahajan R, et al. Risk factors for visceral leishmaniasis relapse in immunocompetent patients following treatment with $20 \mathrm{mg} / \mathrm{kg}$ liposomal amphotericin B (Ambisome) in Bihar, India. PLoS Negl Trop Dis. 2014;8(1):e2536.

17. Sundar S. Drug resistance in Indian visceral leishmaniasis. Trop Med Int Health. 2001;6(11):849-854.

18. Murray HW. Prevention of relapse after chemotherapy in a chronic intracellular infection: mechanisms in experimental visceral leishmaniasis. J Immunol. 2005;174:4916-4923.

19. Murray HW. Treatment of visceral leishmaniasis in 2004. Am J Trop Med Hyg. 2004;71(6):787-794.

20. Takele Y, Abebe T, Weldegebreal T, et al. Arginase activity in the blood of patients with visceral leishmaniasis and HIV infection. PLoS Negl Trop Dis. 2013;7(1):e1977.

21. Mira JA, Corzo JE, Rivero A, et al. Frequency of visceral leishmaniasis relapses in human immunodeficiency virus-infected patients receiving highly active antiretroviral therapy. Am J Trop Med Hyg. 2004;70(3):298-301.

22. Pineda JA, Gallardo JA, Macías J, et al. Prevalence of and factors associated with visceral leishmaniasis in human immunodeficiency virus type 1-infected patients in Southern Spain. J Clin Microbiol. 1998;36:2419-2422.

23. Ritmeijer K, ter Horst R, Chane S, et al. Limited effectiveness of highdose liposomal amphotericin B (AmBisome) for treatment of visceral leishmaniasis in an Ethiopian population with high HIV prevalence. Clin Infect Dis. 2011;53(12):e152-e158

24. Burza S, Mahajan R, Sinha PK, et al. Visceral leishmaniasis and HIV co-infection in Bihar, India: long-term effectiveness and treatment outcomes with liposomal amphotericin B (AmBisome). PLoS Negl Trop Dis. 2014;8(8):e3053.

25. Mahajan R, Das P, Isaakidis $\mathrm{P}$, et al. Combination treatment for visceral leishmaniasis patients coinfected with human immunodeficiency virus in India. Clin Infect Dis. 2015;61:civ530.

26. Sinha PK, Griensven J, Pandey K, et al. Liposomal amphotericin B for visceral leishmaniasis in human immunodeficiency virus-coinfected patients: 2-year treatment outcomes in Bihar, India. Clin Infect Dis. 2011;53(7):e91-e98.
27. ter Horst R, Collin SM, Ritmeijer K, Bogale A, Davidson RN. Concordant HIV infection and visceral leishmaniasis in Ethiopia: the influence of antiretroviral treatment and other factors on outcome. Clin Infect Dis. 2008;46:1702-1709.

28. Cota GF, de Sousa MR, de Mendonça AL, et al. Leishmania-HIV co-infection: clinical presentation and outcomes in an urban area in Brazil. PLoS Negl Trop Dis. 2014;8(4):e2816.

29. WHO. Manual on Visceral Leishmaniasis. Geneva: WHO; 1996.

30. Yimer M, Abera B, Mulu W, Zenebe Y, Bezabih B. Proportion of visceral leishmaniasis and human immune deficiency virus co-infection among clinically confirmed visceral leishmaniasis patients at the endemic foci of the Amhara National Regional State, North-West Ethiopia. Am J Biomed Life Sci. 2014;2(1):1-7.

31. Lima IP, Müller MC, Holanda TA, Harhay M, Costa CH, Costa DL. Human immunodeficiency virus/Leishmania infantum in the first foci of urban American visceral leishmaniasis: clinical presentation from 1994 to 2010. Rev Soc Bras Med Trop. 2013;46(2):156-160.

32. de La Rosa R, Pineda JA, Delgado J, et al. Incidence of and risk factors for symptomatic visceral leishmaniasis among human immunodeficiency virus type 1-infected patients from Spain in the era of highly active antiretroviral therapy. J Clin Microbiol. 2002;40:762-767.

33. Albuquerque LC, Mendonça IR, Cardoso PN, et al. HIV/AIDS-related visceral leishmaniasis: a clinical and epidemiological description of visceral leishmaniasis in northern Brazil. Rev Soc Bras Med Trop. 2014;47(1):38-46.

34. Hurissa Z, Gebre-Silassie S, Hailu W, et al. Clinical characteristics and treatment outcome of patients with visceral leishmaniasis and HIV co-infection in northwest Ethiopia. Trop Med Int Health. 2010;15(7):848-855.

35. WHO. Indicators for Monitoring and Evaluation of the Kala-Azar Elimination Programme. Genave: WHO; 2010.

36. Mengistu G, Ayele B. Visceral Leishmaniasis and HIV co-infection in patients admitted to Gondar University Hospital, Northwest Ethiopia. Ethiop J Health Dev. 2007;21(1):53-60.

37. Palella FJ Jr, Delaney KM, Moorman AC, et al. Declining morbidity and mortality among patients with advanced human immunodeficiency virus infection. HIV Outpatient Study Investigators. $N$ Engl J Med. 1998;338:853-860.

38. Carr A, Marrito D, Field A, Vasak E, Cooper DA. Treatment of HIV1-associated microsporidiosis and cryptosporidiosis with combination antiretroviral therapy. Lancet. 1998;351:256-261.

39. Berman J. Visceral leishmaniasis in the New World and Africa. Indian J Med Res. 2006;123:289-294.

40. Fernandez Cotarelo MJ, Abellan Martinze J, Guerra Vales JM, et al. Effect of highly active antiretroviral therapy on the incidence and clinical manifestations of visceral leishmaniasis in HIV infected patients. Clin Infect Dis. 2003;37(7):973-977.

41. Lyons S, Veeken H, Long J. Visceral leishmaniasis and HIV in Tigray, Ethiopia. Trop Med Int Health. 2003;8(8):733-739.
HIV/AIDS - Research and Palliative Care

\section{Publish your work in this journal}

HIV/AIDS - Research and Palliative Care is an international, peerreviewed open-access journal focusing on advances in research in HIV, its clinical progression and management options including antivira treatment, palliative care and public healthcare policies to control viral spread. The journal welcomes original research, basic science,

\section{Dovepress}

clinical \& epidemiological studies, reviews \& evaluations, expert opinion \& commentary, case reports \& extended reports. The manuscript management system is completely online and includes a very quick and fair peer-review system. Visit http://www.dovepress.com/ testimonials.php to read real quotes from published authors. 